\title{
Mediaalisuudet ja modaalisuudet
}

Jarkko Toikkanen 
edioista ja uusista esittämisen muodoista keskusteltaessa kirM jallisuudentutkijat kohtaavat käsitteellisen sekamelskan, jossa vilahtelevat termit mediaalisuus ja modaalisuus ja etuliitteet kuten inter-, trans-, multi- ja re-/de-. Mitä tutkija tarkoittaa, kun hän käyttää jotain käsitettä, ja miten käsiteyhdistelmät eroavat toisistaan? Maailmalla asiasta on eri koulukuntia. Mannermainen tutkimus saattaa esimerkiksi keskittyä mediasta toiseen toistuvien ilmiöiden diakroniseen kehittymiseen (Balestrini \& Bergmann 2018; Wolf 2011; Rajewsky 2005), kun taas angloamerikkalainen tutkimus voi pyrkiä korostamaan mediateknologioiden materiaalisia ja ideologisia ominaisuuksia (Stewart 2010; Bolter \& Grusin 2000; Mitchell 1994). Käsiteyhdistelmät ovat pitkään olleet Suomessa käytössä mediatutkimuksessa (Herkman, Hujanen \& Oinonen 2012), taiteiden tutkimuksessa (Heinonen 2014) ja käännöstieteessä (Oittinen \& Tuominen 2007), mutta jaetun dialogin perusta puuttuu, eikä aihepiiriä koostavaa esitystä taida olla julkaistu sitten Kai Mikkosen Kuva ja sana -kirjan (2005).

Haasteena olisikin toimittaa tieteenalojen teoreettisia lähtökohtia ja menetelmiä yhdistävä uusi suomenkielinen artikkelikokoelma. Toteutus voisi ottaa mallia kansainvälisistä teoksista (Rippl 2015; Herzogenrath 2012), joihin taiteiden-, kielten- ja kulttuurintutkijat ovat kirjoittaneet nykypäivän mediaalisuuksien ja modaalisuuksien tutkimisen poikkitieteellisestä muutoksesta. Kotimaisen kokoelman vahvuutena voisi olla paikallisten ominaispiirteiden tunnistaminen - millaista työtä meillä tehdään ja missä? Havainnollistan tarvetta esimerkillä.

Olen tutkinut ilmiötä, jota nimitän intermediaaliseksi kokemukseksi - eli sitä mitä kirjallisuuden lukija lukiessaan kuvittelee aistivansa (Toikkanen \& Virtanen 2018; Hatavara \& Toikkanen 2017; Toikkanen 2017a, 2017b, 2014, 2013). Lähestymistapani on koettu omintakeiseksi, koska intermediaalisuuden käsitteellä yleensä viitataan kuvaa, sanaa, ääntä ja vaikkapa liikettä yhdisteleviin taiteenlajeihin tai mediaformaatteihin kuten teatteriin, sarjakuvaan ja peleihin. Tutkimus voi tällöin olla multimodaalinen analyysi, joka selvittää, miten intermediaaliset esitykset välittävät merkityssisältöjä erilaisin semioottisin keinoin (Elleström 2014; Kress 2009). Toisaalta tarkastelun lähtökohta voi olla kognitiivinen, jolloin huomio keskittyy siihen, millaisin mentaalisin ja kehollisin ärsykkein esitys aktivoi lukijansa tai yleisönsä (Pettersson 2016; Brosch 2015). Molemmissa tapauksissa tulkinta ja mielikuvitus heräävät ja johtavat analyyttisiin havaintoihin esityksen äärellä syntyneestä kokemuksesta.

Semioottiset ja kognitiiviset lähestymistavat sopivat myös yhteen, kuten Suomen Akatemian "The Literary in Life: Exploring the Boundaries between Literature and the Everyday" -konsortiohankkeen kesäkuussa Tampereella järjestämässä kansainvälisessä LILI18-konferenssissa nähtiin. Kun tutkija 
Kolmannen portaan käsitteelliset abstraktiot auttavat

hahmottamaan, miten muun muassa kirjallisuus ilmiönä

tai jokin intermediaalinen esitys kulttuurisena teoksena

sekä ammentaa ympäristöstään että vaikuttaa siihen.

kartoittaa tietyn teoksen merkityssisältöjä liittyen esimerkiksi teemoihin tai konteksteihin, teoksen kyky kiinnittää lukijansa luotuun tarinamaailmaan ja sitä elävöittäviin hahmoihin on tärkeässä roolissa. Jos kuvitelma jättää kylmäksi eikä anna ajattelemisen aihetta, sen yhteydet tähänkään todellisuuteen tuskin jaksavat kiinnostaa. Mikäli taas vire pysyy yllä, ja tutkija etsii jotain kättä pidempää, yksi vaihtoehto on transmediaalinen narratologia (Thon 2017; Ryan \& Thon 2014). Kun teoksen tarinamaailma hahmoineen liikkuu yhdestä kertomisen ja esittämisen tavasta toiseen - kuten kirjallisuudesta peleihin tai elokuviin ilmiötä voi tutkia kerronnallisen esittämisen transmediaalisena strategiana. Se mahdollistaa esitysten rakenteellisten ja temaattisten vastaavuuksien tunnistamisen eri medioissa. Jan-Noël Thon valaisi kuulijoitaan aiheesta yhtenä LILI18:n kutsupuhujista. Transmediaalisen narratologian voi myös ymmärtää yhden esittämisen tavan erityispiirteiden tarkasteluna ketterin menetelmällisin välinein, kuten Mikkonen (2017) on viime vuosina osoittanut soveltaessaan sarjakuvatutkimukseen tuttuja kertomuksentutkimuksen käsitteitä kuten mimesis ja diegesis, fokalisaatio ja mielenkuvaus.

Oma tutkimusmenetelmäni ei ole ristiriidassa semioottisten ja kognitiivisten lähestymistapojen kanssa vaan luo retorisia siltoja niiden välille. Intermediaaliset esitykset vaikuttavat lukijaansa ja yleisöönsä erityisin tavoin, jotka ilmenevät niin merkityssisältöjä välittävien merkkien muotoina ja rakenteina kuin vastaanottajia aktivoivina ärsykkeinä. Kutsun tätä erityisyyttä välinemääräisyydeksi (medium-specificity). Sanoihin perustuva, kuvaton ja äänetön kirjallisuus vaikuttaa lukijaansa toisin kuin sarjakuva, jossa kuva on fyysisesti 
läsnä, kun taas ensiksi mainitussa kaikki aistihavainnot ovat kuviteltavissa. Televisiossa, elokuvassa, tietokonepeleissä ja sosiaalisessa mediassa kuva ja ääni ovat fyysisesti läsnä, ja keinotodellisuusohjelmat pyrkivät lisäämään kokemukseen tunto-, haju- ja makuhavainnot samoin kuin virtuaalisen tilan tajun.

Tutkimuksessani olen käyttänyt retorisia laitteita (device) kuten ekfrasis ja hypotypoosi erittelemään intermediaalisten esitysten vaikutustapoja. Molemmat laitteet saavat kokijansa kuvittelemaan näköön tai muuhun aistiin perustuvia aistihavaintoja. Toisin kuin hypotypoosi, joka tuottaa vain eläväisen aistihavainnon, ekfrasis asettuu välittömästi tulkinnallisen kehykseen (mitä havainnoin ja mitä se tarkoittaa). Kehittämäni välineisyyden (mediality) kolmiportaisen mallin avulla tunnistan, miten toiselle portaalle sijoittuvat esittämisen tavat kuten kirjallisuus, televisio ja sosiaalinen media hyödyntävät ensimmäisen portaan aistihavaintoja (kuva, ääni, tunto, haju, maku), jotka ovat joko kuviteltuja tai fyysisesti läsnä. Kolmannen portaan käsitteelliset abstraktiot taas auttavat hahmottamaan, miten muun muassa kirjallisuus ilmiönä tai jokin intermediaalinen esitys kulttuurisena teoksena sekä ammentaa ympäristöstään että vaikuttaa siihen. Kokonaisuutena malli mahdollistaa monenlaisten media-aineistojen retorisen välinemääräisyyden analysoinnin poikkitieteellistä metodologiaa soveltaen.

LILI18 jätti tunnelman, että hihat kannattaa kääriä Suomessa tehtävän mediaalisuuksien ja modaalisuuksien tutkimuksen kentän yhdistämiseksi kirjallisuustieteistä yhteiskuntatieteisiin, taiteiden tutkimuksesta mediatutkimukseen ja käännöstieteeseen. Urakan voi aloittaa pyrkimällä jaetun dialogin perustamiseen puheenvuoroissa, julkaisuissa ja seminaareissa, jotka johtavat yhteisiin hankkeisiin. Tällaisena aloitteena mainittakoon Tampereella syyskuussa pidetty Intermediality and Narrative -työpaja, jonka paikallinen Narrare-tutkimuskeskus järjesti yhdessä Ruotsin Växjössä sijaitsevan Linnaeus University Centre for Intermedial and Multimodal Studies (IMS) -tutkimuskeskuksen kanssa. Toinen tulevien tapahtumien suunnitteluun osallistuva yhteistyökumppani on itävaltalainen Centre for Intermediality Studies in Graz (CIMIG). Parhaimmillaan kansainvälinen yhteistyö eri tieteenalojen edustajien kanssa tuottaa uudenlaisia synteesejä koulukuntien kesken ja paljastaa lupaavimmat kehittymisen suunnat.

\section{Lähteet}

Balestrini, Nassim Winnie \& Ina Bergmann (toim.) 2018. Intermediality, Life Writing, and American Studies: Interdisciplinary Perspectives. Berlin \& Boston: de Gruyter.

Bolter, Jay David \& Richard Grusin (toim.) 2000. Remediation: Understanding New Media. Cambridge: MIT Press. 
Brosch, Renate 2015. Images in Narrative Literature: Cognitive Experience and Iconic Moments. Teoksessa Cabriele Rippl (toim.), Handbook of Intermediality: Literature-Image-Sound-Music. Berlin \& Boston: de Cruyter, 343-360.

Elleström, Lars 2014. Media Transformation: The Transfer of Media Characteristics among Media. Basingstoke: Palgrave Macmillan. https://doi.org/10.1057/9781137474254

Elleström, Lars 2019. Transmedial Narration: Narratives and Stories in Different Media. Basingstoke: Palgrave Macmillan.

Hatavara Mari \& Jarkko Toikkanen 2017. The Sensational World of The Running Man. Teoksessa Merja Polvinen, Maria Salenius ja Howard Sklar (toim.), Mielikuvituksen maailmat: Tieteidenvälisiä tutkimuksia kirjallisuudesta / Fantasins världar: Tvärvetenskaplig litteraturforskning / Worlds of Imagination: Explorations in Interdisciplinary Literary Research: Essays in Honor of Prof. Bo Pettersson. Turku: Eetos, 182-202.

Heinonen, Yrjö (toim.) 2014. Taide, kokemus ja maailma. Risteyksiä tieteidenväliseen taiteiden tutkimukseen. Turku: UTUkirjat.

Herkman, Juha, Taisto Hujanen \& Paavo Oinonen (toim.) 2012. Intermediality and Media Change. Tampere: Tampere University Press.

Herzogenrath, Bernd (toim.) 2012. Travels in Intermedia[lity]: ReBlurring the Boundaries. Lebanon: Dartmouth College Press.

Kress, Gunther 2009. Multimodality: A Social Semiotic Approach to Contemporary Communication. London \& New York: Routledge. https://doi.org/10.4324/9780203970034

Mikkonen, Kai 2005. Kuva ja sana: kuvan ja sanan vuorovaikutus kirjallisuudessa, kuvataiteessa ja ikonoteksteissä. Helsinki: Gaudeamus.

Mikkonen, Kai 2017. The Narratology of Comic Art. New York \& London: Routledge. https://doi. org/10.4324/9781315410135

Mitchell, W. J. T. 1994. Picture Theory. Chicago \& London: The University of Chicago Press.

Oittinen, Riitta \& Tiina Tuominen (toim.) 2007. Olennaisen äärellä. Johdatus audiovisuaaliseen kääntämiseen. Tampere: Tampere University Press.

Pettersson, Bo 2016. How Literary Worlds Are Shaped: A Comparative Poetics of Literary Imagination. Berlin \& Boston: De Gruyter. https://doi.org/10.1515/9783110486315

Rajewsky, Irina O. 2005. Intermediality, Intertextuality, and Remediation: A Literary Perspective on Intermediality. Intermediality / Intermédialités, No 6 automne: 43-64.

Rippl, Cabriele (toim.) 2015. Handbook of Intermediality: Literature-Image-Sound-Music. Berlin \& Boston: de Gruyter.

Ryan, Marie-Laure \& Jan-Noël Thon (toim.) 2014. Storyworlds across Media: Toward a Media-Conscious Narratology. Lincoln: University of Nebraska Press.

Stewart, Garrett 2010. Bookwork as Demediation. Critical Inquiry, 36(3), 110-157. https://doi. org/10.1086/653407

Thon, Jan-Noël 2017. Transmedial Narratology Revisited: On the Intersubjective Construction of Storyworlds and the Problem of Representational Correspondence in Films, Comics, and Video Games. Narrative 25(3), 286-320. https://doi.org/10.1353/nar.2017.0016

Toikkanen, Jarkko 2019. Intermedial Experience and Ekphrasis in Wordsworth's "Slumber". Partial Answers, erikoisnumerossa "Narrative Selves", 17(1), 107-124.

Toikkanen, Jarkko 2017a. Auditory images in Edgar Allan Poe's "The Tell-Tale Heart". The Edgar Allan Poe Review, 18(1), 39-53. https://doi.org/10.5325/edgallpoerev.18.1.0039

Toikkanen, Jarkko 2017b. Välineen käsite ja välinemääräisyys 2010-luvulla. Media \& viestintä, erikoisnumerossa "Totuus, valhe, media ja viestintä", 40(3-4), 69-76.

Toikkanen, Jarkko 2014. Failing description in Edgar Allan Poe's "The Black Cat". Teoksessa Kaisa Koivisto, Jani Kukkola, Timo Latomaa \& Pirkko Sandelin (toim.), Kokemuksen tutkimus IV. Annan kokemukselle mahdollisuuden. Rovaniemi: Lapin yliopistokustannus, 270-281. 
Toikkanen, Jarkko 2013. The Intermedial Experience of Horror: Suspended Failures. Basingstoke: Palgrave Macmillan. https://doi.org/10.1057/9781137299093

Toikkanen, Jarkko \& Ira A. Virtanen (toim.) 2018. Kokemuksen tutkimus VI. Kokemuksen käsite ja käyttö. Rovaniemi: Lapland University Press.

Wolf, Werner 2011. (Inter)mediality and the Study of Literature. CLCWeb: Comparative Literature and Culture 13/3. http://docs.lib.purdue.edu/clcweb/vol13/iss3/2 (tieto haettu 19.9.2018). 